Рената Ясавеева

\title{
К ПОНЯТИЮ ФИЛОСОФСКОЙ РИТОРИКИ ЧЕРЕЗ ОПЫТ ЧТЕНИЯ МАКСА ШТИРНЕРА
}

Аннотация. В данной статье я обращаюсь к книге Макса Штирнера «Единственный и его собственность», чтобы использовать ее в качестве примера философской риторики понятия, которым я предлагаю описывать намеренно многозначные тексты, которые особенно характерны для континентальной школы мысли. Философская риторика нужна мне для прояснения того, в чем основание извечного конфликта толпы и философа. Как я предполагаю, это основание заключается в различных способах относиться к миру, который выражается и в чтении текстов. В статье последовательно рассматриваются три возможных уровня интерпретации Макса Штирнера. Вывод, который я делаю, состоит в том, что философская риторика оказывается, с одной стороны, политической стратегией вычленения себе друзей среди потенциально враждебного общества. С другой стороны, она незаменима в деле воспитания философов и мыслителей, поскольку сразу позволяет понять, есть ли у человека желание мыслить или он решает посредством чтения совершенно иные задачи.

Ключевые слова: риторика, философия, способы чтения, Штирнер, философ, толпа.

\section{Renata Yasaveyeva}

\section{TOWARDS THE CONCEPT OF PHILOSOPHICAL RHETORIC THROUGH THE EXPERIENCE OF READING MAX STIRNER}

Abstract. In this article, I turn to Max Stirner's book The Ego and His Own to use it as an example of philosophical rhetoric. I propose the concept to describe deliberately ambiguous texts that are especially characteristic of the continental school of thought. I need philosophical rhetoric to clarify what is the basis of the eternal conflict between the crowd and the philosopher. As I suppose, this foundation lies in different ways of relation to the world, which is also expressed in the way of reading of texts. The article sequentially examines three possible levels of interpretation of Max Stirner. The conclusion I draw is that philosophical rhetoric turns out to be, on one hand, a political strategy for isolating friends for oneself among a potentially hostile society. On the other hand, it is indispensable in the education of philosophers and thinkers, since it immediately makes it possible to understand whether a person has a desire to think, or wants to solve completely different problems through reading.

Keywords: rhetoric, philosophy, ways of reading, Stirner, philosopher, mass.

\footnotetext{
${ }^{1}$ Ясавеева Рената Искэндэровна - магистрантка программы «Социально-политическая философия», центр практической философии «Стасис», Европейский университет в Санкт-Петербурге. Renata Yasaveyeva, student of the Graduate Program in Social and Political Philosophy, Stasis Center for Practical Philosophy, European University at St. Petersburg. yasaveyeva@gmail.com
} 
ЛОГИКА И ФИЛОСОФИЯ

Для цитиРовАния: Ясавеева Р. И. К понятию философской риторики через опыт чтения Макса Штирнера // Логико-философские штудии. 2020. Т. 18, № 4. С. 328 339. DOI: 10.52119/LPHS. 2021. 88.31 .003 .

\section{1. Введение. Что такое философская риторика? О достоинствах и недостатках философии Макса Штирнера}

История книги Макса Штирнера «Единственный и его собственность» (1844г.) известна: когда книга вышла в печать, тираж собирались арестовать, но затем это действие посчитали излишним, так как мысли философа были сочтены слишком абсурдными, чтобы представлять собой какую-либо опасность (Welsh 2010: 14). Будучи популярным среди последователей философа, сам по себе этот эпизод не обладает какой-то особенной значимостью, однако есть другой факт: внушительная часть книги Штирнера посвящена «одержимым» - толпе, образ мысли которой он, правда, называет исключительно опасным - скорее всего, в контексте своей философии эгоизма. Такая взаимная перебранка является не случайной и напоминает о важной и древней проблеме политической философии, интересовавшей еще Платона, - проблеме различия мыслителя и толпы, которое находит выражение в скрытом или явном конфликте․ Моей задачей в этом тексте будет прояснение сути этого конфликта - в той степени, в какой философия эгоизма позволяет это сделать.

Макс Штирнер выбран мной не только из-за формального повода в виде риторического столкновения с обществом - были в истории и более яркие случаи. Но, прежде чем перейти к объяснению, мне хотелось бы отметить два дополнительных обстоятельства, которые выделяют Штирнера на фоне прочих. Их можно интерпретировать по-разному, как достоинства или как несовершенства, но для моего вопроса эти обстоятельства оказываются очень полезными - и я с удовольствием пользуюсь ими.

Во-первых, хотя можно согласиться с тем, что многое из говоримого Штирнером можно глубже понять через чтение Хайдеггера, Кожева, Деррида и других континентальных мыслителей (Хаустов 2020: 7), по сравнению с ними у него присутствует то, что с трудом можно обнаружить у тех, кто сделал себе из философии «ремесло». Философское кредо Штирнера - это радикальная честность, граничащая с беззастенчивостью, и, конечно, наслаждение, следы которого носит его книга. Не то чтобы эти черты отсутствуют у других философов, просто у Штирнера они буквально бросаются в глаза. Можно спорить о том, насколько успешна такая

\footnotetext{
${ }^{2} Я$ намеренно не провожу в этом тексте различия между философом и мыслителем, поскольку это тема для совершенно отдельного размышления.
} 
Рената Ясавеева. К понятию философской риторики...

стратегия, или о том, насколько она является сознательной, а не обусловленной «непрофессионализмом»: в конечном счете, Штирнер явно менее популярен, чем С. Кьеркегор, К. Маркс и Ф. Ницше, а такие влиятельные историки философии, как Карл Лёвит, отводят ему скромную роль в плеяде младогегельянцев (Левит 2002). В любом случае, намеренно ли ценой собственной популярности или случайно, Штирнер в своей философии демонстрирует условия мысли, без которых она невозможна.

Вторую особенность тоже можно воспринимать двояко: «Единственный и его собственность» - это единственная книга Макса Штирнера, который обширных трудов больше не писал. Такая ситуация являет собой контраст с теми философами, которых мы изучаем в современной академии, и которые пишут всю свою жизнь. Был ли Штирнер просто посредственным философом или мы имеем дело с подлинным мудрецом, который, объяснив мир, перешел к практике прямо в своей жизни? На уровне некоторых тезисов можно обнаружить совпадение между словами философа и его жизнью:

«С мышлением обстоит дело так же, как со всякой другой работой, которую ты можешь бросить, когда захочешь» (Штирнер 2020: 430).

В этом смысле, даже если идеи Штирнера были ошибочными, нет сомнения в том, что подлинное философствование такое совпадение подразумевает.

Чем же философия Штирнера полезна в контексте прояснения конфликта мыслителя и толпы?

Его книга представляет собой то, что я предлагаю называть философской риторикой. Смысл ее в том, что она обнажает суть интересующего меня конфликта. Как это возможно? Позволяя воспринимать сказанное различными способами, такая риторика позволяет читателю свободно выразить свое к ней отношение, которое очевидно, отличается у мыслителя и у обычного человека. Отношение к тексту, строго говоря, ничем не отличается от отношения к другим вещам и к миру вообще, выражая то, что составляет основу образа жизни человека. Так, философская риторика позволяет прояснить суть противостояния мыслителя и толпы.

Очевидно, что Штирнер - это не единственный, кто применяет философскую риторику, однако в силу указанной эксцентричной честности он оказывается наиболее удобен для прояснения того, как эта риторика работает. Как известно, наиболее значимая академическая дискуссия о Штирнере посвящена выяснению того, считать ли его гегельянцем и диалектиком (рассматривая более формально) или софистом, экзистенциалистом и постструктуралистом (делая больший акцент на стиль его письма) $)^{3}$. Кроме того, его идеи часто изучают в контексте политической

\footnotetext{
${ }^{3} \mathrm{O}$ многогранности ярлыков, наклеенных на Штирнера, можно судить по работам современных историков философии (например: Ridder 2007, Welsh 2010).
} 
философии и истории анархизма (Antliff 2007). И хотя такие «сложные» случае способны давать материал для все новых и новых статей, такая свобода интерпретации все же является минусом для тех, кто пытается разобраться, «как оно на самом деле».

Я, однако, предлагаю взглянуть на текст с совершенно иной - более практической - стороны; ведь именно к этому Штирнер призывает с такой страстностью. Позволяя воспринимать сказанное разными способами, книга «Единственный и его собственность» позволяет читателю свободно выразить свое к ней отношение. Различное у мыслителя и у толпы, оно в пределе и является основанием для их конфликта. При этом - хотя это в некотором роде вторично - есть основания считать, что такая риторика полностью соответствует цели Макса Штирнера, которую он преследует, создавая свою книгу.

Логика моей работы следующая. Я собираюсь последовательно рассмотреть три возможных способа восприятия текста Штирнера: логический (отвечающий на вопрос «что сказано?»), стилистический («кто говорит?») и политический («как это меняет существующий порядок вещей?»). Первый способ основывается на интуиции здравого смысла и на том, как Штирнера обычно предлагают воспринимать академические статьи, ему посвященные. Второй способ менее очевиден, но и его можно найти в ряде академических работ, а также, к примеру, у Жиля Делеза в книге, посвященной Ф. Ницше (Делез 2003). Третий способ я, соответственно, вывожу из философии эгоизма Макса Штирнера.

\section{2. Логический способ чтения. Мыслитель глазами толпы}

Итак, первый способ чтения - формальный, логический. Если следовать тексту таким образом, философ Макс Штирнер утверждает, что он открывает новый мир, и, чтобы обосновать его возможность, рассказывает историю, которая развивается диалектически. Если смыслом истории по Гегелю является сознание свободы, то двигательным механизмом истории Штирнера является акт присвоения отчужденных форм собственности (Делез 2003: 318). Мир порождает людей, и древние люди борются с миром, чтобы он стал их собственностью, а не вмешивался бы в их жизнь. Эта борьба ведется с помощью духа, и через некоторое время мир становится человеку внешним и спокойным: человек живет в нем, но равнодушен к нему. Этот новый человек оказывается полностью духовным существом, он находится в рабстве у духа: мир передан ему его «отцом». Как следствие, человек зависим от него так же, как до этого был зависим от мира. Поэтому в эпоху христианства люди вынуждены бороться уже не с миром, но с духом. Наконец, дух тоже становится человеку внешним, симптомом чего выступает безразличие к любым его содержательным проявлениям. Современный Штирнеру человек живет духовными сущностями (идеями, поэтому любая идея по Штирнеру навязчива), любит абстрактной любовью «человека как такового», но в действительности все 
Рената Ясавеева. К понятию философской риторики...

идеи и истины находятся к нему в отношении чуждости. Третья, современная эпоха, провозвестником которой вроде бы объявляет себя Штирнер, подразумевает, что настало время человеку освобождать себя от духа - будь то дух в виде религии или политических течений (либерализма, коммунизма или социализма), которые являются ее трансформированными формами.

Эти три эпохи, согласно Штирнеру, совпадают с тремя стадиями развития человека:

«Ребенок жил реальностями, он был во власти земного, пока ему не удалось разгадать, что стоит за всем; юноша был идеалистом, его воодушевляли мысли, пока он не достиг возмужалости, не сделался эгоистическим зрелым человеком, который по своему произволу распоряжается реальностями и мыслями и ставит свой личный интерес выше всего. А что же старец? Об этом будет время поговорить, когда я состарюсь» (Штирнер 2020: 39).

Основная проблема Штирнера, соответственно, такова: как сделаться взрослым, как освободиться из-под гнетущей власти духа, чтобы пользоваться им, как сделать его собственностью «Я»? Очевидно, что под тем «Я», с помощью которого следует освободиться от власти духа и которое до сих пор оставалось отчужденным, Штирнер понимает тело человека (Штирнер 2020: 197). Если сначала человеку требовалось завоевать для себя мир с помощью духа, то теперь необходимо завоевать дух с помощью тела. Об этом свидетельствует и завершение процитированной фразы: с телом, как полагает Штирнер, не будет никакой проблемы, потому что тело освобождает человека от себя само с течением времени.

При таком способе прочтения сразу возникает две серьезные проблемы, которые связаны с восприятием Штирнера как гегельянца. На первую указал Карл Маркс в «Немецкой идеологии» (Маркс, Энгельс 1998), вторую отмечает Жиль Делез.

Штирнер утверждает, что все христианские идеи, идеи воспитания, усовершенствования и призвания бессмысленны, поскольку человек в любом случае «разворачивается» настолько, насколько может, подобно тому как «цветок не следует призванию усовершенствовать себя, а между тем он употребляет все свои силы, чтобы как можно больше насладиться миром и использовать его...» (Штирнер 2020: 403). Философ, таким образом, призывает использовать свое тело в борьбе против духа, но не проясняет, какая между ними связь, или даже отрицает ее, сравнивая тело с цветком. Фактически это значит, что человек бессилен и не может ничего изменить.

Именно это является ключевым пунктом критики Карла Маркса: он утверждает, что Штирнер не говорит ничего по существу, что его тезис тривиален:

«Индивиды всегда и при всех обстоятельствах „исходили из себя“, но, так как они не были единственны в том смысле, чтобы не нуждаться ни в какой 
связи друг с другом - ибо их потребности, т. е. их природа и способ их удовлетворения, связывали их друг с другом (отношения между полами, обмен, разделение труда), - то им необходимо было вступать во взаимоотношения друг с другом» (Маркс, Энгельс 1998: 411).

Человек и так всегда использует свое тело, просто оно устроено таким образом, что изначально нуждается в общении с другими телами, а дух - это и есть способ этой связи. Более того, если речь идет о теле, то оно развивается не только в меру заложенной в нем самом потенции, но и в силу тех условий, в которых оно находится, - то есть оно зависимо также и от других тел. Поэтому Маркс предлагает менять через политику материальные условия, в которых находится тело человека, в то время как человек у Штирнера вынужден довольствоваться тем миром, который есть, а значит, состоянием рабства у духа (Левит 2002: 226). Иными словами, Штирнер, с одной стороны, критикует точку зрения религиозности, которая подразумевает, что человек есть только дух, но он и сам с точки зрения Маркса оказывается на той же позиции, считая, что одного только знания и духовного решения достаточно, чтобы человек стал взрослым.

Вторая проблема связана с возможностью этики. Первая часть книги Штирнера - это раскрытие истории, предшествующей современности, вторая часть это попытка ответить на вопрос, что же в этой современности делать, как принадлежать самому себе полностью, пользоваться миром, духом и телом в личных интересах. Подразумевается, что современная эпоха начнется тогда, когда люди начнут поступать в соответствии с той этикой, которую предлагает Штирнер. Однако при наличии истории, самостоятельно совершающейся по законам диалектики, этика бессмысленна. «Все и так сделают за меня» - такова мысль, которая автоматически ввергает человека в состояние нигилизма:

«Смысл слитых воедино истории и диалектики - не воплощение разума, свободы или человека как вида, но нигилизм, ничего кроме нигилизма. Штирнер - это диалектик, открывший нигилизм как истину диалектики» (Делез 2003: 321).

Получается, если читать Штирнера как диалектика, его книга оказывается совершенно бесполезна. Я исхожу здесь из предположения, что, если человек читает текст, он рассчитывает получить некое представление о мире, которое было бы, во-первых, непротиворечивым, а во-вторых, его можно было бы применить на практике. Но Штирнер из такой перспективы вообще отрицает возможность практики! Это способно принести большое разочарование, поэтому можно предположить, что обвинение в нелепости или абсурде - это следствие неоправданных ожиданий. Такой способ чтения - и такая реакция - и являются для Штирнера признаком толпы, которую он определяет через разочарование и неудовлетворенность (Штирнер 2020: 187). 
Рената Ясавеева. К понятию философской риторики...

\section{3. Стилистический способ чтения. Мыслитель глазами критика}

Второй, стилистический, способ восприятия текста подразумевает, что буквальное прочтение является несправедливым, поскольку оно безразлично к слишком многим деталям философии Штирнера; многие ее моменты смотрятся не абсурдно и неосмысленно. Конечно, Штирнер создает крайне абстрактную историю, действующими лицами которой являются человечество, дух, бог, государство, человек, но все эти сущности соседствуют у него рядом с бабушкой, скалами, цветами:

«,Видал ли ты когда-нибудь привидения?““ — „Нет, я не видал, но моя бабушка видала“. Вот так и со мной. Я тоже никаких привидений не видел, но моей бабушке они постоянно попадались под ноги, и, веря честности бабушек, мы верим в существование духов. 〈... Пусть проваливаются горы, пусть увядают цветы и разрушаются звездные миры, пусть умирают люди - что в гибели этих видимых тел? Дух, „невидимый“ дух вечен» (Штирнер 2020: 60-61).

Более того, если сначала Штирнер пишет свою историю в согласии с конвенциональными обозначениями исторических периодов (античность, периоды раннего христианства, гуманизма, Реформации), то затем он повторяет ее, но так, как будто бы ее последовательно творят три расы: негроподобная, монголоподобная и кавказская (Штирнер 2020: 97). И здесь уже никакие соображения не спасают от чувства абсурда, а потом от смеха, потому что становится понятно отношение Штирнера к тому, что он говорит. Для него все исторические «истины» и другого рода сущности имеют такой же статус, как его остроумные выдумки, это и подчеркивает его альтернативная версия признанной истории.

Так, ключевая идея философии эгоизма — Я, сущность которого состоит в ничто и отрицании, - состоит как раз в лишении бытия любых сущностей и понятий, будь то мир, дух или тело: Штирнер действительно разбрасывает камни (Хаустов 2020: 17). Его Я, таким образом, способно отрицать даже миф о собственном появлении, если только это понадобится. История является лишь материалом, на котором можно продемонстрировать Я в действии, и она сразу же уходит на второй план, когда начинается самая важная - вторая - часть философского текста, под названием «Я», а таков изначальный вариант заглавия всей книги.

Таким образом, диалектика и история у Штирнера в лучшем случае ироничны и являются пародией на Гегеля, чем представляют собой что-то серьезное国. Смысл того сдвига, который Штирнер осуществляет своей философией, состоит в том, что кантовский вопрос «что такое человек?», который подразумевает ответ в виде понятия или сущности, Штирнер заменяет вопросом «кто?», который

\footnotetext{
${ }^{4}$ Того же мнения придерживается ряд современных академических авторов, в противоположность интерпретациям прошлого века (Ridder 2007).
} 
«...вообще уже не вопрос, ибо ответ покоится в личности вопрошающего; ответ дан уже самим вопросом» (Штирнер 2020: 450).

Единственное, что может иметь значение, в противоположность любой абстрактной истине, - это своеобразие человека. Своеобразие подразумевает наклонности, характер, способности, волю и ряд случайно заданных внешних условий. Подразумевается, что разного рода обобществленные истины и идеи мешают человеку увидеть это своеобразие, поэтому отказаться от истин и идей нужно, чтобы понять, что он может, чего он хочет, и затем использовать себя для достижения собственных, а не чужих и обобществленных целей, которые возникают из общего определения человека.

В таком прочтении задача Штирнера очень близка задаче киников. Помимо того, что он буквально повторяет их аргумент против идей Платона, его целью в этом тексте ока-зывается не сообщить способ действия, а продемонстрировать его. Вольный стиль его письма, граничащий с абсурдом, - это и есть проявление своеобразия Штирнера, и, каза-лось бы, он отчетливо призывает читателя к тому, чтобы последовать за ним:

«Своеобразие зовет вас к самим себе... Тысячелетия культуры затмили вас от вас самих, вселяя в вас веру, что вы не эгоисты, а призваны быть иделистами („хорошими людьми“). Стряхните это с себя!» (Штирнер 2020: 207)

Так, можно подумать, что целью Штирнера является пробуждение человека, здесь и сейчас, в процессе чтения, посредством пафоса и едких вопросов. Проблема в том, что эта киническая цель - это цель критика. То, что это так, достаточно убедительно показывает Мишель Фуко в своих лекциях, посвященных киникам (Фуко 2014). Согласно Фуко, они практикуют парресию (в одном из ее значений) - бесстрашную или искреннюю речь. Часть ее элементов действительно можно найти у Штирнера: это высказывание, совершаемое от себя, необходимое соответствие логоса и биоса (о том, что в случае Штирнера это имеет место, было упомянуто во введении), определенное мужество, в котором философу нельзя отказать, так как все же его идеи были достаточно радикальны для своего времени.

Вместе с тем, необходимым элементом парресии является бескорыстие и критическая функция. Если понимать цель Штирнера таким образом, как специфического киника, то это будет противоречить его собственным словам, так как на протяжение всей книги Штирнер раз за разом пытается отделить себя от критики и сказать, что его дело - это не критика:

Если бы я был критик... то я вел бы борьбу за свободное мышление против порабощающей мысли, защищал бы мышление против уже продуманного. Но я не борец за какую-нибудь мысль или за мышление, ибо Я, из которого я исхожу, не мысль и не заключается в мышлении» (Штирнер 2020: 191). 
Рената Ясавеева. К понятию философской риторики...

Штирнер утверждает, что критики - все еще зависимы, в то время как он (будучи, конечно, мыслью) отказывается от борьбы, поскольку борющийся зависим от того, против чего он борется. В этом смысле Штирнер и утверждает, что критик и сам принадлежит «массе», то есть толпе.

Таким образом, Штирнер тщательно предохраняет себя от того, чтобы потенциальный критик счел его своим другом - и критик в данном случае тоже окажется разочарованным. Примером такого критика может служить, очевидно, Маркс. Он высмеивает Штирнера, представляя его в виде нелепой фигуры, но делает это, во-первых, с позиции исторического материализма и сущностей вроде индивида, истории и диалектики, которые для эгоиста в принципе не важны. Во-вторых, критик игнорирует тот факт, что Штирнер сам отказывается от роли критика ему вообще не нужно изменять мышление или сознание людей.

Так, поскольку стилистический способ прочтения при определенной последовательности приводит именно к критике, выясняется, что этот способ чтения, хотя он и более внимателен, чем первый, не прикасается к коренной идее штирнеровской философии - к сути эгоизма.

\section{4. Политический способ восприятия: толпа глазами мыслителя}

Штирнер прямо в своем тексте отбрасывает предположение о том, что его цель это возвестить новый век или пробудить читателя ото сна. Более того, он был бы крайне непоследовательным антигегельянцем, если бы хотел признания или сущностного определения своего времени или считал бы очень осмысленным ученичество, которое предполагает, что ученик внимательно слушает учителя. Предыдущие способы чтения текста схватывают лишь материал, с помощью которого Штирнер демонстрирует, как нужно правильно взаимодействовать с миром через отрицание любых сущностей помимо себя. Тот, кто этого не делает, является несвободным эгоистом, который цепляется за что-то высшее и сам служит материалом для отрицания кого-то другого. Этот человек и будет для Штирнера одержимым в том классическом смысле, что он оказывается врагом самому себе.

Если смысл отношения эгоиста к миру действительно может быть описан через идею творческого ничто, то получается, что таково же и отношение Штирнера к читателям, о чем он им и сообщает:

«Я вижу, что люди окружены толпой призраков и живут в темном суеверии. Если я стараюсь, насколько у меня есть сил, пролить свет в эту ночную мглу, то разве я это делаю из любви к ним? 〈... Нет, я пишу, потому что хочу дать бытие моим мыслям... 〈...〉 Делайте из этого, что хотите и что можете; это ваше дело, и оно меня не тревожит. Быть может, мои мысли принесут вам только огорчения, борьбу и смерть, и лишь очень немногие испытают от них радость. 〈...〉Я пою - потому что я певец. Вами же я пользуюсь, потому что 
мне нужны уши» (Штирнер 2020: 367).

Таким образом, Штирнер предоставляет читателю самому определиться с тем интересом, который движет им, когда он берет в руки его книгу, но сам он руководствуется совершенно иными соображениями. Философ говорит не для кого-то, не ради чего-то, и получается, что он пишет его исключительно для самого себя и самому себе - ради собственного наслаждения. Отличие Штирнера от других мыслителей состоит разве что в том, что он говорит это не один раз, по сути делая на этом акцент. Но значит ли это, что на этом исчерпывается цель написания его работы и тот смысл, которым он ее наделяет?

Одной из ключевых идей Штирнера является так называемый союз эгоистов, который он противопоставляет жизни в государстве, в коммунизме или любом другом объединении, принцип которого дан его участникам в качестве заранее сформированного. Однако союз не может состоять только из одного человека. Политическое пространство подразумевает, что речь всегда идет о формах общения, а значит, что успешность идеи эгоизма, как ни парадоксально, во многом зависит от того, будут ли у нее союзники. Поэтому цель написания и публикации этой книги, будучи эгоистичной, все же имеет в виду благо других — правда, подобных Штирнеру — читателей, которые смогут понять его идеи.

Отличительной особенностью этих читателей будет, во-первых, увлеченность не столько содержанием и выводами книги, сколько самим процессом мысли и творчества. Во-вторых, их отношение к идеям Макса Штирнера будет подобным ему - они будут воспринимать то, что он говорит, не как урок, а как материал; тем самым они окажутся намного более последовательны в практике его идей, чем те, кто будет прислушиваться к его словам (Lucet 2018). В-третьих, эти читатели, собственно, будут единственными, кто сможет задать вопрос о том, что в мире изменяет факт существования этой книги - потому что оно изменит именно их бытие.

Жизнь эгоиста в мире, населенном несвободными эгоистами, трудно назвать счастливой: он вызывает скуку, раздражение и вину, которые феноменологически описывает Штирнер. Поэтому, если предположить, что книгу эту читает именно такой человек, то в процессе чтения он объединяется с автором в тот самый союз эгоистов - он учится мыслить мир через общение (взаимоотношение, действие), которое Штирнер противопоставляет сообществу (Штирнер 2020: 272). Тем самым мир для этого читателя совершенно меняется, поскольку политически он становится гораздо сильнее, чем до этого, он уже не просто ничто, под которым подразумевается человек политически бесправный - именно на такую жизнь, жизнь преступника обречен человек, поступающий против сообщества. Просто ничто трансформируется в творческое ничто, причем это творчество оказывается прежде всего политическим, поскольку оно начинается с объединения. Поскольку то, что объединяет мыслителя и такого читателя, - это уже отнюдь не внеш- 
Рената Ясавеева. К понятию философской риторики...

ние факты, а особенный способ отношения к миру, к тексту, друг к другу. Это и есть процесс того, как ничто становится творческим в том смысле, что происходит изобретение новых способов связи между двумя или более людьми.

Таким образом, именно последний способ чтения помогает прояснить, что в основе конфликта толпы и мыслителя основе его лежит, во-первых, необходимость отстаивать свой образ жизни для одной стороны: одержимость толпы есть что-то, что является потенциально опасным для эгоиста и в силу многочисленности, и в силу определенных ограничений. Толпа же, напротив, называет мыслителя нелепым и испытывает скорее разочарование, смешанное с подозрением, чем опасение.

\section{5. Заключение и практический вывод}

Философская риторика Макса Штирнера помогает прояснить смысл неприязни мыслителя и толпы. Непримиримость их проявляется не столько в содержании их риторики (то есть через некое «существо дела»), сколько в исходном отношении к внешнему миру. Трудность, которая состоит в том, что об отношении говорить довольно сложно, Штирнер решает весьма интересным способом: он позволяет читателю свободно проявить себя в интерпретации и тем самым отнести себя к одной из двух сторон. Кто-то, подобно историкам философии, будет спорить о том, кем же в действительности является Штирнер, какова его действительная сущность или какую картину мира он предлагает, - для него это, пожалуй, наихудший вид читателей. Другие, которые не являются мыслителями, будут разочарованы, потому что ничего содержательного о том, как правильно действовать, Штирнер не говорит. Единственный императив, императив отрицания, в пределе означает необходимость отрицать даже сами идеи Штирнера. Такие читатели, соответственно, уйдут от Штирнера к Марксу, который более конкретно скажет, кто враг, как нужно с ним бороться и т. п. Наконец, будут те, кто попытается уловить смысл штирнеровской философии и воспользоваться им для собственных целей.

В современности противостояние мыслителя и толпы маскируется — по крайней мере, если говорить об академическом и неакадемическом мирах. Но для этого и нужна философская риторика и философия эгоизма; в последнем улавливается главная предпосылка философствования или мысли: только сам человек может являться ее источником, все прочее является всего лишь мнением, а жить в соответствии с мнением или чьим-то наставлением для философа является абсурдом, сумасшествием, это вообще значит не жить, а существовать как призрак.

Так, я могла бы предположить, что книги вроде той, что написал Макс Штирнер, «Единственный и его собственность», исключительно полезны в силу своей искренности, и их стоит давать читать на первых курсах философского факультета. Будучи написанной исключительно простым языком и представляя собой образец философской риторики, такие книги позволяют понять, кто из читателей 
хочет и способен мыслить, а кто нет. Для первых это сделало бы пространство университета свободным от посторонних людей, а вторым сэкономило бы время жизни.

\section{Литература}

Делез 2003 - Делез Ж. Ницше и философия. М.: Ad Marginem, 2003.

Левит 2002 - Левит K. От Гегеля к Ницше. Революционный перелом в мышлении XIX века. СПб.: Владимир Даль, 2002.

Маркс, Энгельс 1998 - Маркс K., Энгельс Ф. Немецкая идеология. Критика новейшей немецкой философии в лице ее представителей Фейербаха, Б. Бауэра и Штирнера и немецкого социализма в лице его раз-личных пророков. М.: Издательство политической литературы, 1998.

Фуко 2014 - Фуко М. Мужество истины: управление собой и другими II. СПб.: Наука, 2014.

Хаустов 2020 - Хаустов Д. Единственный и его автор // Штирнер М. Единственный и его собственность. М.: Рипол Классик, 2020. С. 6-26.

Штирнер 2020 - Штирнер М. Единственный и его собственность. М.: Рипол Классик, 2020 .

Antliff 2007 - Antliff A. Anarchy, Power, and Poststructuralism // SubStance. 2007. Vol. 26, no. 2, Issue 113: The Future of Anarchism. P. 56-66.

Koch 1997 - Koch A. M. Max Stirner: The Last Hegelian or the First Poststructuralist? // Anarchist Studies. 1997. Vol. 5. P. 95-108.

Lucet 2018 - Lucet A. L'éducation comme création de soi chez Max Stirner // Astérion. Vol. 19. DOI: 10.4000/asterion. 3625.

De Ridder 2007 - De Ridder W. Max Stirner, Hegel and the Young Hegelians: A reassessment // History of European Ideas. 2007. Vol. 34, no. 3. P. 285-297.

Welsh 2010 - Welsh J. F. Max Stirner's Dialectical Egoism: A New Interpretation. Minneapolis: Lexington Books, 2010. 